\title{
ALEXANDRIA
}

Revista de Educação em Ciência e Tecnologia

ALEXANDRIA

\section{Visão Epistemológica de Timothy Lenoir: A Produção Cultural das Disciplinas Científicas}

\section{The Epistemological View of Timothy Lenoir: The Cultural Production of the Scientific Disciplines}

\author{
Neusa Teresinha Massoni ${ }^{\mathrm{a}}$; Marco Antonio Moreira ${ }^{\mathrm{a}}$ \\ a Instituto de Física, Universidade Federal do Rio Grande do Sul, Porto Alegre, Brasil - neusa.massoni@ufrgs.br, \\ moreira@if.ufrgs.br
}

Palavras-chave:

Timothy Lenoir.

Disciplinas científicas.

Indústria. Produção

cultural.
Keywords:

Timothy Lenoir.

Scientific disciplines.

Industry. Cultural

production.
Resumo: O objetivo deste texto é interpretar e divulgar algumas ideias de Timothy Lenoir a partir de seus estudos de caso dos desenvolvimentos da Alemanha Imperial e do Vale do Silício, que mostram como o avanço científico pode resultar do diálogo entre diferentes atores: academia, indústria e Estado e da indissociabilidade entre teoria e técnica. Lenoir toma a ciência como uma atividade interessada, em que o aspecto técnico e instrumental é crucial ao seu desenvolvimento. Defende que a instituição de disciplinas científicas está, muitas vezes, associada a múltiplos interesses sociais, profissionais e industriais: as indústrias tornam-se usuárias das ideias científicas ao mesmo tempo em que contribuem com produtos, técnicas e na construção de institutos de pesquisa; a universidade, por sua vez, contribui com inovação que leva à criação de novas empresas de base tecnológica. Nesse sentido, dissociar teoria e técnica, pesquisa básica de pesquisa aplicada nem sempre é possível. Às vezes, ciência e indústria estão "muro a muro" contribuindo mutuamente e gerando desenvolvimento.
Abstract: The purpose of this text is to interpret and disseminate some ideas of Timothy Lenoir from his case studies about developments, in the Imperial Germany and the Silicon Valley, which show that the scientific advancement might result from the dialogue between different actors: academia, industry, state; from the inseparability between theory and technique. Lenoir considers science as an interested activity, in which the instrumental and technical aspects are crucial for its development. He argues that the institution of scientific disciplines is, in many cases, associated to multiple social, professional, and industrial interests: the industries become users of scientific ideas and at the same time they contribute with products, techniques, and in the construction of research institutes; the university, in turn, contributes with the innovations that generate the creation of new technologically based enterprises. In that sense, it is not always possible to dissociate theory and technique, or basic and applied research. Sometimes, science and industry are "wall to wall" mutually contributing and generating development. 


\section{Introdução}

A interpretação e divulgação de distintas visões epistemológicas aumenta a probabilidade dos professores de distintos níveis de ensino promoverem discussões em sala de aula, auxiliando, assim, no desenvolvimento de concepções menos ingênuas, elitistas e individualistas da ciência. A recorrência a estudos de caso e episódios históricos vem sendo sugerida como uma das possibilidades de contextualizar tais discussões sobre a natureza da ciência no ensino de Física e de ciências em geral (PEDUZZI, 2001; MARTINS, 2006; LEDERMAN, 2007; BATISTA et al., 2015).

Em geral, conhecem-se e discutem-se as visões de epistemólogos proeminentes do século passado. O que se pretende neste trabalho é avançar e apresentar aspectos relevantes da visão de Timothy Lenoir, norte-americano, professor e diretor do Programa de História e Filosofia da Ciência da Universidade de Stanford; pensador recente na linha de uma epistemologia menos centrada na teoria e mais focada na tecnociência, sem negar a importância da teoria, como tentaremos mostrar ao longo do texto.

Este texto foi construído a partir da leitura atenta da obra de Lenoir intitulada Instituindo a Ciência, publicada originalmente em 1997 (LENOIR, 2004) e de artigos e textos de outros autores que, de alguma forma, mostraram-se correlacionados à sua postura epistemológica. Trata-se, portanto, de uma introdução às ideias de Lenoir, de forma que para um aprofundamento é indispensável consultar suas obras originais. Algumas implicações de sua visão também são discutidas de forma breve.

A interpretação e o destaque aqui dados a alguns aspectos de sua visão da natureza da ciência e das disciplinas científicas seguiu, em grandes linhas, um aporte metodológico de análise de conteúdo inspirada em Bardin (2004), guiada por três polos cronológicos básicos: pré-análise; exploração dos materiais; tratamento dos resultados e interpretação. Através deste processo privilegiamos alguns aspectos temáticos que estão expressos no presente trabalho na forma de subtítulos. Através de um exercício de leitura e releitura buscamos encontrar coerência na interpretação e, em alguns momentos, recorremos a comparações com distintas ideias e situações históricas.

É importante destacar que não se trata de um trabalho de investigação norteado por questões de pesquisa em que dados empíricos são coletados, analisados e interpretados à luz de algum referencial teórico. Mas pensamos que nem por isso perde a relevância de ser compartilhado com a comunidade da área de pesquisa em ensino de ciências.

Umberto Eco em uma obra endereçada a seus estudantes explica:

Quando se fala de "descoberta” especialmente em ciências humanas, não se pensa em invenções extraordinárias (...) pode haver descobertas modestas também, e é considerado "científico" também um modo novo de ler e compreender um texto clássico, a identificação de um manuscrito que lança nova luz sobre a biografia de um autor, uma reorganização e releitura de estudos precedentes que traz a maturação 
e sistematização de ideias que vagam dispersas em vários outros textos. (ECO, 2016, p. 16-17, tradução nossa).

É nesta linha que o presente texto foi pensado. Em outras palavras, o que se busca é perceber, introdutoriamente pelo menos, como as ideias de Timothy Lenoir podem ser compreendidas na tentativa de contribuir para o nosso entendimento "do que" seja e "como" se faz ciência, assim como de seu papel na sociedade. $O$ desenvolvimento de um conhecimento científico não é tão simples, como muitas vezes se deixa transparecer (RAICIK, PEDUZZI, 2016) e para entender esse processo o contexto da descoberta precisa ser levado em conta. Mas não só. O contexto social, econômico, político, industrial podem lançar luz sobre nossas próprias concepções de ciência.

\section{Ciência: uma prática sócia interessada e não autônoma}

Timothy Lenoir toma a ciência como uma prática técnica em uma dinâmica de relações entre indústria e universidade para formar o que ele chama economias disciplinares contemporâneas (LENOIR, 2004, p. 5). E assume:

(...) enfatizo a maneira como essa ciência, na condição de prática cultural, está imbricada em uma rede sem costuras com outras formas de práticas sociais, políticas, inclusive estéticas e eu trato a formação de disciplinas e das instituições científicas como sítios para a construção e sustentação de formas de identidade social e cultural, situadas relativamente a esses outros corpos culturais. Minha estratégia para elaborar essa estrutura é oferecer estudos de caso que reexaminam certas junções cruciais no quadro histórico... (ibid., p. 14).

O autor emprega a metáfora dos metaversos $^{1}$ - possível no mundo virtual dos computadores - para sugerir que também as disciplinas científicas guiam, coordenam e incorporam habilidades, de maneira que os inexperientes, ou novatos, precisam se aculturar, adquirir tais competências sob pena de se "esborracharem contra as paredes de concreto" das disciplinas (ibid., p. 12). Sua análise centra-se na dinâmica da instituição de novas disciplinas científicas no contexto das universidades, especialmente na pesquisa alemã do século XIX, e a problemática relação que emergiu entre ciência, indústria e Estado na virada do século XX e no período pós-guerras. Para melhor compreender esse processo, Lenoir começa por destacar certos aspectos da visão da sociologia de ciência de Robert Merton (1973) e Joseph BenDavid (1971), as quais Lenoir toma como contraponto à sua visão.

Para esses sociólogos (MERTON, 1973; BEN-DAVID, 1971) a ciência prospera dentro de uma estrutura organizacional espefícica (e.g., a Física e a Medicina): i) é

\footnotetext{
${ }^{1}$ Metaversos são abstrações que existem apenas em realidades virtuais, em que os jogadores desenvolvem habilidades (como o hacker ninja Hiro) e são guiados por regras (por exemplo, em Snow Crash, romance de Neal Stephenson, "você pode passar através dos avatares e de outras pessoas. Mas você não pode passar através das paredes. Você não pode invadir uma propriedade privada... ou através de instalações permanentes, como os Portos...").
} 
essencialista (estaria em busca de leis universais, enquanto a Sociologia busca identificar condições sociais e culturais em relação às quais a ciência é um valor de direito próprio, independente das conexões com outras instituições e com tecnologia, por exemplo); ii) existe sob certas normas (é desinteressada, busca do conhecimento pelo conhecimento, livre de contextos sociais, ideológicos e econômicos; é universal e cética): cresce independentemente dos interesses sociais (economia, indústria, religião) e desenvolve-se em sociedades de "certo tipo" (daí a importância da unificação do ensino e da pesquisa nas universidades alemãs, destaca ele), marcada por um mercado descentralizado (liberal e competitivo para o talento científico) e por um ambiente autônomo, imparcial e assentado no realismo (vivemos em um mundo real de fenômenos e processos tal que as teorias devem corresponder com esse mundo); iii) é objetiva, parte da noção de que há no mundo fatos objetivos que independem de interpretações, expectativas e mesmo da presença das pessoas; iv) é autônoma, os contextos econômico e social só desempenham algum papel quando há a negativa de apoio ou tentam intervir nas suas normas, nestes casos acabam desviando a ciência de sua meta. Em suma, para esses sociólogos, a ciência é tipicamente vocacional e desinteressada e por essa razão insistem na distinção entre ciência pura e aplicada; a preocupação com a aplicação desvia e corrompe a busca desinteressada do conhecimento. A tecnologia é, para eles, uma ciência aplicada mediante a aplicação e o refinamento da teoria.

Lenoir discorda do modelo realista-objetivista (de Merton e Ben-David) em vários aspectos, desde a caracterização da ciência, até suas normas, em especial a autonomia e o desinteresse. Defende que o conhecimento é o engajamento com o mundo em uma relação interpretativa, de onde se segue que, para mim, tal conhecimento é necessariamente interessado ${ }^{2}$ - no sentido de que a ciência não é uma vocação ou uma busca do conhecimento sobre o mundo natural não motivada pelo interesse social ou econômico utilitário (LENOIR, op. cit., p. 17).

Argumenta ele que há contradições nas visões sociológicas da ciência e que estas o levaram a repensar a "institucionalização da ciência" a partir de um novo ponto de vista: de abandono das noções de desinteresse e autonomia. Considera que questões de distinção, prestígio, reconhecimento e luta por recursos financeiros têm se tornado inseparáveis da ciência. Assim, “desinteresse e autonomia são idealizações artificialmente impostas sobre a prática de poucos engajados na construção do conhecimento científico” (ibid., p. 19).

Para Lenoir, a ciência é duplamente interessada, tem tanto os interesses sociais e econômicos (de todos os atores envolvidos na construção do conhecimento) quanto cognitivo

\footnotetext{
${ }^{2}$ Neste texto usamos o termo desinteressada para nos referirmos à crença (criticada por Lenoir) de que a ciência caracteriza-se como uma atividade vocacional, cuja meta primordial é a busca do conhecimento pelo conhecimento e que tal atividade independente dos interesses de classe ou econômicos com fins utilitaristas.
} 
(atua e interpreta o mundo), de maneira que é uma prática social, institucionalmente apoiada. Esses interesses estão implicados um no outro e isto é crucial para que a ciência seja tomada como uma prática cultural, na visão deste pensador.

\section{A virada pragmática}

Lenoir, inspirado na análise da tradição sociológica de Pierre Bourdieu (1977), que vê a construção do conhecimento científico simultaneamente como uma tentativa de definir a sociedade e de legitimar a visão das pessoas a respeito da realidade social, reconhece o cálculo racional como crucial, mas distingue lógica da racionalidade teórica. Para ele, racionalidade científica "é sempre um conjunto de movimentos, de procedimentos, sejam teóricos ou pragmáticos, num laboratório, sejam quais forem, a cujo conjunto chega-se através de negociação e, por fim, através de consenso de modo a manter o funcionamento da comunidade científica" (REGNER; LEAL, 1997, p. 134). Com isso assume uma visão de ciência como tecnociência. A prática científica para Lenoir tem sua própria lógica, que nada tem a ver com a lógica da representação teórica. Com isso assume uma visão de ciência como tecnociência.

Regner e Leal (ibid.) apontam que Lenoir critica o conceito de racionalidade da epistemologia de Kuhn, Lakatos e outros, por considerá-lo dominado pelo enfoque na "teoria"; centrado na explicitação e articulação de uma teoria que uma comunidade adquire, incorporando a dimensão social que marca o trabalho científico. Mas, adverte que há em Kuhn um conceito de irracionalidade no sentido de que se a "ciência normal" falha, as razões lógicas são insuficientes para dar conta da mudança (ou "revolução científica") que se segue.

Retomando Bourdieu, Lenoir defende o caráter histórico "situado" da ciência, isto é, ela depende do tempo, dos planos e de ações práticas. Esse caráter, segundo ele, forçou-o a olhar para a prática, para a instrumentação e manipulação de aparelhos de laboratório e para a relação dessas ações com a representação teórica dos seus "objetos". Assim, distinguir a ciência pura da ciência aplicada não pode mais ser tomado como óbvio.

O foco na prática expande o horizonte de inquirição sobre a produção do conhecimento científico. A instrumentação, o experimento e o trabalho interpretativo prático são mostrados como simultaneamente participando em uma economia de interesses sociais, políticos e culturais, dissolvendo dessa forma a distinção entre interno e externo da história e sociologia tradicionais da ciência (LENOIR, ibid., p. 21).

Essas práticas científicas seriam parte do que Pierre Bourdieu chama de capital simbólico e capital cultural, noção que rejeita a ideia da busca desinteressada, independente de interesses sociais e econômicos. Para Bourdieu, capital simbólico seria a educação, ato de presentear, competência, honra ou respeitabilidade, ou seja, tudo o que é oposto a bens materiais e econômicos; capital cultural seria determinado pelos diversos tipos de bens 
culturais e educacionais, bem como a trajetória de vida dos sujeitos. Bourdieu rejeita a visão de que a busca de bens simbólicos e culturais seja desinteressada e defende que, ao contrário, é uma prática fortemente configurada como transação social e econômica. Para ele, todas as formas de capital (simbólico, cultural, político) são interconversíveis e cada classe tem um polo dominante e um dominado. defende ele que os grupos profissionais tais como acadêmicos têm alto grau de capital, tanto econômico quanto cultural, mas ocupam o polo dominado na esfera de poder. No entanto, a chave para o poder dentro de uma classe é uma questão contingente determinada pelo próprio campo em questão. No campo econômico quem determina o poder é a posse de poder econômico. No campo cultural a lei do sucesso é definida em termos de produção de criação de valor (valor da arte e da ciência em si mesmas, e o reconhecimento do cientista como criador de objetos valorizados).

Inspirado nessas ideias, Lenoir argumenta que esse mesmo princípio estruturador opera dentro da academia. Alguns campos dentro da academia são mais próximos do poder econômico, têm ligações com a indústria, com o governo - a ciência, por exemplo, ao passo que campos nas artes e humanidades são relativamente independentes de interesses políticos e econômicos. Assim, no final da década de 1990, físicos trabalhando em amplos laboratórios governamentais fundados na Guerra Fria, forjaram novas alianças de pesquisa com a indústria, as quais, segundo Lenoir, estão redefinindo a ciência básica de uma forma antes impensável.

No entanto, ele argumenta que não está interessado em tratar as posições intelectuais assumidas pelos indivíduos como reflexo de sua classe, tampouco de seus interesses intelectuais declarados ou seu trabalho científico como formas disfarçadas de interesses sociais. "Em vez disso, defendo um exame cuidadoso das condições de produção do trabalho científico em questão e das relações sociais que lhe dão suporte” (ibid., p. 26).

Entende ele que o trabalho científico é impensável sem as condições objetivas que o originam e lhe dão suporte. Daí a importância de tomar como objeto de estudo não apenas a teoria científica ou produtos publicados (artigos científicos, livros), mas também o trabalho científico e as condições objetivas que entram na criação, circulação e reprodução de produtos de qualquer campo determinado.

Dentro dessa perspectiva, o autor de um texto científico ou de uma teoria é apenas o nó mais visível de toda uma rede de relações sociais, incluindo autores de outros textos científicos, com quem ele discute ou em quem se apoia, editores, fazedores de instrumentos, assistentes de laboratório, administradores do Estado e da Universidade e, possivelmente, até mesmo fornecedores comerciais de equipamentos e especialidades (ibid., p. 27).

Lenoir chama essa abordagem de história contextualista, pois focaliza a formação de instituições científicas e suas relações (como interações dinâmicas de grupos interessados), e 
afirma que essa história merece maior atenção, dado que pouco é tratada em outras abordagens epistemológicas.

Nos episódios históricos por ele examinados, argumenta Lenoir, há um tema que se repete: a observação de que declarações na esfera da teoria, do método, da técnica e do estilo são, além de questões de disputa substantiva, estratégias sociais em que poderes são afirmados e reivindicados. Em qualquer campo científico, acrescenta ele, a primeira parada é a luta pela definição exata do próprio campo: seus objetivos, seus métodos de investigação legítima, seus procedimentos para resolver disputas e sua alocação de recursos. Para entender essa dinâmica é importante compreender que nenhum campo, não importando quão autônomo ele pareça, é fechado a fatores externos. Os fatores externos são alavancas cruciais para a dinâmica do campo científico.

\section{O diálogo entre teoria e experimentação}

Instrumentação, experimentação e procedimentos de medida constituem o corpo de práticas que formam a cultura técnica da ciência, mas Lenoir reclama que a interpretação filosófica tem sido hostil às suas contribuições. A história da ciência é quase sempre escrita como a história da teoria (ibid., p. 36).

No entanto, segundo ele, algumas discussões têm fornecido elementos para garantir uma relativa autonomia à experimentação, por exemplo: Hacking (1983) defende que a experimentação tem vida própria, que o investigador moderno formula metas de investigação e pode, ocasionalmente, estender os meios técnicos até o limite de inventar novos meios técnicos para investigar dado fenômeno; Cartwright (1983) sugere que a construção de modelos é o elo entre os domínios da teoria e da prática, mas os modelos não são todos dedutíveis da própria teoria, ao contrário, dentro de uma mesma teoria pode haver vários modelos mutuamente inconsistentes.

Há também, lembra Lenoir, microestudos em que o contexto é limitado ao laboratório, que representam um dos extremos do espectro da abordagem contextualista, por exemplo, a obra Vida de laboratório de Latour e Woolgar (1997) que toma o fato científico como uma construção social. Lenoir, todavia, considera essa abordagem dominada pela teoria já que Latour e Woolgar afirmam que o objetivo principal do laboratório é produzir artigos de alto valor na literatura e pouca importância atribuem às técnicas experimentais em si mesmas. Em contraste ao estudo de Latour e Woolgar, Lenoir entende que é útil considerar o estudo de Frederic Holmes (1985), Lavoisier e a química da vida, que dá menos ênfase aos aspectos sociais cruciais e enfatiza uma perspectiva interacionista mais complexa, especificando loops de retroalimentação que ligam teoria e prática naquilo que Holmes chama de unidades investigativas limitadas, no sentido de que Lavoisier não tinha inicialmente uma teoria da 
respiração para guiar seus experimentos, às vezes os experimentos eram separados e até conflitantes, e só adquiriram coerência quando ele, finalmente, começou a colocar suas ideias no papel. Mesmo antes de desenvolver os conceitos que permitiram moldar de forma coerente suas investigações, Lavoisier não procedia às cegas porque não tinha uma teoria, mas tinha metas investigativas e era um "raciocinador prático" (LENOIR, 2004, pp. 43-44). Os cientistas criativos, segundo a descrição de Holmes (1985), mantêm uma rede de empreendimentos investigativos, com caminhos investigativos distintos e da interação entre as diferentes tendências experimentais surgem conceitos que são reunidos de forma coerente em teorias, sendo que o processo de rascunhar artigos e a colaboração com outros cientistas formam o contexto apropriado de diálogo entre experimentação e teoria.

Outro estudo examinado por ele é o de Andy Pickering (1987), Formas de vida: ciência, contingência e Harry Collins, em que fenômenos naturais vêm embrulhados em aptidões técnicas experimentais e a sintonia (simbiose) de práticas e teorias é fonte de teorias. Para Pickering (1987), “as práticas dos físicos teóricos fornecem um contexto reforçador para as práticas dos experimentalistas, e vice-versa" (Lenoir, 2004, p. 50). O resultado dessa sintonização de conceitos, práticas e ferramentas de cada uma dessas comunidades é a emergência de uma forma de vida culturalmente específica, de um mundo autossuficiente de práticas teóricas e experimentais e é um processo socialmente contingente.

\footnotetext{
Em contraste com o modelo desenvolvido por Latour e Woolgar, nem tudo vale para Pickering. Além disso, como Holmes, ele pensa que a natureza não é completamente maleável e passível de ser moldada de acordo com os caprichos de grupos de cientistas. A ênfase na prática e no diálogo, envolvendo aparelhagem técnica, manipulação experimental e formação de conceitos, assegura que a produção do conhecimento não seja puramente fortuita. Na explicação de Pickering, a dinâmica da prática é estruturada pela distribuição e pelo acesso aos recursos materiais e conceituais dentro de contextos sociais (LENOIR, op. cit., p. 51).
}

Além desses, Lenoir examina outros microestudos e conclui que há uma falta de unidade nas discussões sobre a prática científica local e que a característica comum dessas abordagens é que são dominadas pela teoria. Consequentemente, o laboratório acaba desaparecendo da explicação e as relações sociais dentro de suas paredes passam a funcionar como caixas pretas nos instrumentos. E as análises filosóficas que se preocupam em distinguir o contexto da descoberta e o da justificação acabam deixando de lado o contexto das práticas em que os fatos são construídos.

Mas há alguns estudos, destaca ele, que prestam mais atenção ao contexto das práticas.

Por exemplo, ao retratarem o trabalho Wiliam Thomson em Física, afirma Lenoir que Crosbie Smith e M. Norton Wise (na obra Energy and empire: a biographical study of Lord Kelvin, de 1989, Cambridge University Press) contextualizam o diálogo entre práticas teóricas e experimentais. Revelam um cientista criativo, para quem a teoria física e a prática experimental, a construção de instrumentos científicos e inventos de medição a serem 
empregados pela indústria estavam profundamente entrelaçados em uma fusão de conhecimento e poder. Desta forma, adverte ele, seria impossível compreender o significado dos conceitos de Thomson sem apreciar a relação de medição (atribuição de valores numéricos a quantidades que considerava dignas de serem medidas, de atribuir um valor da coisa medida) com a indústria. O laboratório de Thomson em Glasgow, Escócia, na era vitoriana, incorporava o conceito de trabalho, mas a máquina a vapor não era apenas uma fonte de trabalho e valor, foi também uma fonte de novos conceitos científicos.

\begin{abstract}
As considerações teóricas de Thomson não eram conceitos desincorporados. De início ele estava pouco preocupado, por exemplo, com a natureza da eletricidade, mas se preocupava antes com sua capacidade de produzir trabalho. Sua teorização estava constantemente voltada para a formação de conceitos que levassem a cálculos e medições práticas. Assim, a conceitualização de sistemas eletrostáticos por meio da analogia com o conceito técnico de uma máquina permitiu-lhe desenvolver uma medida absoluta para a intensidade elétrica em relação ao efeito mecânico que ela produzia. (...). A máquina a vapor tornou-se, assim, incorporada na própria instrumentação científica que estava assentando a fundação da segunda onda de industrialização (ibid., p. 61).
\end{abstract}

Tal introdução de elementos instrumentais e econômicos, e a ideia relacionada de uma economia das práticas, é foco da visão de ciência de Lenoir.

\title{
Formação de disciplinas científicas
}

De maneira geral, para Lenoir, os microestudos da prática científica local mostram uma falta de unidade na ciência. Mas ele argumenta que é possível perceber na agenda de pesquisa de estudos da ciência recente a emergência de propostas em que o experimento e as tradições de instrumentação têm vidas próprias independentes da mão orientadora da alta teoria, em contraste com as antigas abordagens dominadas pela teoria.

Obras mais recentes (e.g., as já citadas visões de ciência de Ian Hacking (1983) e Nancy Cartwright (1983)) têm insistido que os objetos da ciência são construídos e estabilizados por meio de instrumentos, um processo de "disciplinar a natureza", de tomar a tecnologia experimental como um modelo para o fenômeno natural (ibid., p. 63).

O resultado dessas agendas de pesquisa, adverte ele, é que têm colocado em primeiro plano a heterogeneidade da ciência, a divisão de tarefas e a dispersão de habilidades essenciais ao trabalho científico. Para Lenoir, a tranquila integração de diferentes aspectos da ciência, que nas explicações dominadas pela teoria eram tidas como garantidas, tem-se tornado ela mesma "objeto de investigação".

Nessa linha, as disciplinas científicas emergem como sítios cruciais, como estruturas em que habilidades são reunidas, entrelaçadas com outros elementos e reproduzidas como conjuntos coerentes e apropriados para a condução da prática científica. Esta definição alinhase em boa medida com esforços (como os de Latour e Woolgar) de considerar o conhecimento como um construção social, consente Lenoir. Mas afirma: "enquanto trato a tecnociência 
como socialmente construída, quero evitar a alegação (para mim sem sentido) de que a natureza (os fatos científicos) é simplesmente uma fabricação inventada" (ibid., p. 66).

Acima de tudo, as disciplinas científicas, para Lenoir, são mecanismos institucionais para regular as relações de mercado entre consumidores e produtores de conhecimento.

Disciplinas não são criadas exclusivamente nas instituições acadêmicas. Para ele, estudos antigos supunham a existência de um fluxo linear de inovação dos ambientes acadêmicos de pesquisa para a indústria e que os profissionais da indústria eram consumidores das disciplinas científicas. Contudo, o foco na prática sugere que dada a importância de instrumentos específicos e do treino de seu uso e interpretação pode-se considerar a indústria como uma parceria ativa no processo de formação de disciplinas, especialmente como produtora de instrumentos. Em muitos casos, os engenheiros e cientistas da indústria por meio de suas atividades instrucionais (no sentido de que é preciso organizar e reforçar habilidades necessárias para conduzir práticas de laboratório, por exemplo) e promocionais ajudam a transformar o núcleo de algumas disciplinas.

Para essa concepção de relação do poder com o conhecimento, destaca ele, é central a noção de que poder não é uma força negativa que pesa sempre contra nós, mas uma fonte construtiva, uma rede produtiva que atravessa todo o corpo social. As relações de poder estão engastadas nas (isto é, são ativadas pelas e exercidas mediante as) regras de formação de discursos. E discurso é uma mercadoria política, segundo Michel Foucault ${ }^{3}$. Porém, para Lenoir, a análise de Foucault das formações discursivas ajuda a conceitualizar as disciplinas, mas não explica a formação das disciplinas.

A consideração das disciplinas como mediadoras para economias de práticas sugere, para explicá-las, lançar mão da metáfora da "mão invisível" do mercado, que ajusta as relações entre produtores e consumidores das ferramentas de produção do conhecimento e os esquemas de ação e percepção necessários para adaptá-los à economia política.

Lenoir argumenta que nos estudos que concebem a ciência como dominada pela teoria, as explicações sobre as disciplinas dividem-se em internalistas e externalistas. Internalistas são as explicações que tomam as disciplinas científicas como produto de teorias científicas importantes que resultam da investigação de uma notável descoberta (por exemplo, o modelo da dupla hélice do DNA é candidato a fundador da Biologia Molecular). Externalistas são explicações que tratam as disciplinas como políticas em seu caráter, dependente da alocação de recursos em que construtores de disciplinas, empreendedores e administradores da ciência teriam um papel crucial (por exemplo, os esforços de Warren

\footnotetext{
${ }^{3}$ Michel Foucault é citado por Lenoir através do livro Power/Knowledge: selected interviews and others writings, New York: Randon House, 1980.
} 
Weaver para usar o dinheiro da Fundação Rockefeller para custear seu sonho de criar a Biologia Molecular).

As duas explicações compartilham, argumenta Lenoir, os "mitos fundadores, que dão destaque seja a teorias fundadoras seja a pessoas fundadoras (usualmente, pais)" (ibid., p. 71). Mas, defende ele, ninguém cria disciplinas. Nem os esforços de pesquisadores singulares, nem os de grupos singulares de pesquisadores de um mesmo campo são suficientes para fundar disciplinas. As disciplinas são mais adequadamente compreendidas como efeitos de sistemas interativos. "ideia de uma economia capta melhor esse tipo de dinâmica" (ibid., p. 72).

Esta definição elimina a distinção entre interno e externo e enfatiza o caráter negociado da produção de bens científicos ${ }^{4}$, trata os cientistas como indivíduos lutando uns com os outros pela distribuição de créditos (créditos que eles só podem adquirir quando exibem competência para produzir bens científicos; por outro lado, crédito é reconversível em comando sobre recursos para a produção de mais bens científicos). O crédito é a base, segundo Lenoir, para a autoridade (política) e a acumulação de capital cultural (científica, acadêmica, técnica).

A abordagem que toma o campo científico como um "caso especial do campo cultural", como um local de disputa é útil para captar a tecnociência contemporânea, que é simultaneamente política e técnica, segundo Lenoir. Para levar adiante um programa investigativo é necessário reunir uma variedade de pessoas cientificamente treinadas, técnicas, instrumentos e um quadro administrativo, a maquinaria heterogênea de uma microeconomia local de práticas.

Tratar as disciplinas como se fossem resultados da atividade de pesquisa, empacotados e destilados na ala de ensino da ciência é uma tentação comum, mas tem o inconveniente de fundir pesquisa e atividade disciplinar, que para ele não são idênticos. Se questionados, a maioria dos cientistas diria que trabalha sobre problemas, não sobre uma disciplina, argumenta Lenoir.

A tecnociência contemporânea, destaca ele, é carregada de prática e instrumentação, mas também está carregada de modos de competição específicos ao campo científico que combinam habilidades e perspicácia organizacional. A organização é tal que os competidores são também os consumidores de seu produto: o conjunto de técnicas, habilidades,

\footnotetext{
${ }^{4}$ Bens científicos são atividades socialmente reconhecidas, dependem da configuração de domínios de ciência. O trabalho teórico e a pesquisa de laboratório que resultam em publicação, mas também muitas outras atividades, podem ser valorizados como bens científicos. Por exemplo, diretores dos mais proeminentes institutos de pesquisa científica e ensino na Alemanha, tais como Rudolf Virchow e Ernst Haeckel, na segunda metade do século XIX eram figuras políticas poderosas não só dentro da academia.
} 
instrumentos, teorias, modelos materializam-se em sistemas experimentais produtivos que são incorporados, mediante o uso, por outros pesquisadores.

Essa combinação heterogênea de construção de disciplinas e pesquisa (habilidades, perspicácia organizacional, autoridade, credibilidade, competição, que resulta na construção de disciplinas de um lado e, de outro, a combinação de competências técnicas e de laboratório com trabalho teórico e aspectos associados à pesquisa) é que distingue o campo científico de outros campos da atividade cultural.

Para conduzir a ciência são necessários recursos financeiros, isto é um ponto óbvio, afirma Lenoir, mas desde o início da sua profissionalização no século XIX, como instituição situada em universidades e burocracias estatais, a ciência não funcionou sem administradores (e. g., auxiliares, burocratas). Estes estão mais preocupados com a necessidade organizacional e administrativa, em estabelecer atribuições, facilitar ligações com outras disciplinas, permitir a transmissão de técnicas e ferramentas conceituais do campo científico a outros grupos (de usuários das disciplinas). Os programas de pesquisa, por sua vez, estão mais preocupados em focar problemas e em legitimar e estender os produtos de sua pesquisa. "Assim, considero útil, ao discutir a formação de disciplinas, distinguir entre programas de pesquisa e programas disciplinares" (ibid., p. 76).

Metas disciplinares às vezes exploram programas de pesquisa como recursos políticos para conquistar certas metas institucionais. Neste ponto Lenoir invoca vários estudos de caso históricos para ilustrar a distinção entre os processos que dirigem a pesquisa e a formação de disciplinas. Por exemplo, o uso eficaz de técnicas e o consenso teórico na óptica fisiológica do século XIX determinou um esforço de pesquisa que envolveu físicos, fisiologistas, psicólogos e oftalmologistas; contudo, a mobilização de esforços e a tentativa de cientistas influentes da época de criar um status disciplinar foram insuficientes para estabelecer institutos e cátedras sobre o assunto; mesmo assim, as contribuições da pesquisa sobre a dióptrica dos olhos e o desenvolvimento de técnicas de medição e instrumentação da pesquisa da visão foram assimilados pelos oftalmologistas, assim como os estudos da visão foram assimilados por fisiologistas e psicólogos. Para Lenoir, o exemplo ilustra a noção heterogênea, dispersa, de programas disciplinares adaptados localmente dentro de uma economia política de práticas que ele defende como "a imagem atual da ciência desunificada, carregada de prática e de instrumentação, e dependente de aculturação" (ibid., p. 98). Isto é, a economia política pode estruturar relações locais entre disciplinas vizinhas, criando nichos ocasionais para a acumulação de inovações, para o acondicionamento de práticas centradas em novos programas de pesquisa. 


\title{
Interesses sociais e a física orgânica de 1847, na Alemanha
}

É natural a preocupação de que a boa ciência possa ser prejudicada quando agendas políticas e alinhamentos ideológicos começam a exercer influências sobre os fundos de pesquisa científica. Lenoir pergunta-se: "está, de fato, o desenvolvimento da ciência tão imune a pressões externas? Não pode a boa ciência ser parte de uma rede inteiriça de instituições políticas e econômicas, sustentada por conjuntos de orientações de valores e por ideologias?" (ibid., p. 99).

Para discutir essas questões, novamente Lenoir recorre a um estudo de caso histórico: o surgimento no século XIX, na Alemanha, da fisiologia experimental que teve ascendência no sucesso intelectual da escola alemã, a chamada física orgânica de cientistas como Helmholtz, Ludwig, Brücke e Emil Du Bois-Reymond.

Lenoir defende que para explicar a expansão da fisiologia experimental nessa época, em que não houve "descobertas" concretas que resultassem em aperfeiçoamento no atendimento à saúde (ou seja, benefícios imediatos à sociedade), é preciso considerar a intersecção de uma variedade de interesses internos e externos à ciência, todos voltados a dirigir apropriadamente o movimento das instituições. De um lado, há interesses pessoais, profissionais e/ou sociais; de outro, os interesses do Estado que deve produzir fundos, formar uma política em um processo que pode envolver interesses variados incluindo o controle social, o bem-estar social, o desenvolvimento econômico e os objetivos culturais mais amplos.

Do ponto de vista interno, havia uma intensa competição dentro de um sistema universitário alemão descentralizado, ambiente em que cientistas talentosos e bem-sucedidos como Helmholtz recebiam convites de outras universidades e faziam aumentar o apoio a suas áreas de pesquisa seja com salários ou recursos como laboratórios e instrumentos. Contudo, com isso, não é possível explicar a enorme expansão da fisiologia experimental na Alemanha, e o papel da física orgânica dentro dela. Para isto, entende Lenoir, é importante olhar para o papel das ciências naturais para a formação da ideologia nas décadas de 1850-60.

\begin{abstract}
Minha hipótese é que, depois do colapso de 1849, o sistema de antigos valores do novo humanismo foi à bancarrota; o cimento espiritual que tinha permitido à sociedade prussiana avançar como uma unidade orgânica tinha sido completamente erodido. (...). Da metade para o final dos anos 1850, uma nova ideologia se forjou; estava baseada na satisfação de interesses materiais, na rejeição de todas as formas de idealismo na vida política e intelectual - uma ênfase, em suma, em poder e realismo (ibid., p. 102).
\end{abstract}

Para Lenoir, tal ideologia forneceu as bases para uma sociedade em mudança ${ }^{5}$, e a física orgânica de 1847 desempenhou um papel significativo na formulação da ideologia

\footnotetext{
${ }^{5}$ A Revolução de 1848, explica Lenoir, foi uma política que se centrou no príncipe Guilherme tomando o leme do Estado e levou o Estado prussiano para uma nova era, mais progressista com uma importante mudança na política de ciência do ministério de cultura e educação.
} 
materialista. Os físicos não só tomaram decisões em nome de seus próprios interesses profissionais e disciplinares, mas também ajudaram a preparar um ambiente cultural e político mais amplo, em que essas atividades fossem avaliadas positivamente e ao mesmo tempo consideradas indispensáveis. "Eles o realizaram tirando vantagem de ou criando um mercado para sua própria especialidade, bem como usando formas existentes de tecnologia social para organizar e controlar esse mercado" (p. 103). A estratégia foi persuadir os públicos relevantes de que a base da posição privilegiada das elites dominantes estava desgastada e que seu conhecimento e seus valores já não eram relevantes para a sociedade e o Estado, sendo que para a nova classe emergente (e seu interesse de governar ou participar do governo) os intelectuais tinham uma importância estratégica. No caso em estudo, a classe emergente (a burguesia industrial emergente) não tinha metas revolucionárias e as circunstâncias históricas favoreceram uma aliança entre os intelectuais e a classe emergente, porque os valores desta puderam ser construídos como um reconhecimento da legitimidade das exigências dos intelectuais. As contribuições científicas do grupo de Berlim, que eram, de fato, consideráveis, constituíram o passaporte dos físicos orgânicos para usar o sistema acadêmico para realizar seus interesses sociais em uma época de decolagem da industrialização alemã (final dos anos 1850 a 1870$)^{6}$.

Esse estudo mostra, segundo Lenoir, que a dinâmica por trás da institucionalização de uma nova especialidade científica não esteve restrita às estruturas institucionais da ciência alemã. Este é o ponto chave da sua discussão: não foi o funcionamento autônomo das estruturas da ciência alemã que levou à emergência da fisiologia experimental. Os cientistas valeram-se de uma pressão de fora do sistema, não porque tivessem organizado um lobby científico, pois não o fizeram, mas concentraram esforços na esfera política cultural moldando uma nova ideologia que, ao mesmo tempo, acomodou os interesses científicos e aqueles dos grupos mais poderosos na Prússia. Isto foi essencial para mudar a tradicional inclinação do Ministério da Cultura (kulturministerium) pelas ciências humanas, à época, em favor das ciências naturais. Essa foi uma função simbólica importante, defende Lenoir, porque o apoio às ciências naturais foi essencial para a indústria, mas não só para ela, pois contribuiu para a criação de um estilo de pensamento apropriado e vital para a modernização da Alemanha (envolveu uma reforma educacional de longo alcance, o desenvolvimento de institutos de pesquisa - na área médica, na química agrícola, na fisiologia e na física - e de disciplinas

\footnotetext{
${ }^{6}$ Para construir essa tese, Lenoir explica que se valeu do material de arquivo e biográfico de Emil Du BoisReymond, Hermann Helmholtz , Carl Ludwig, Ernst Brücke, Werner Siemens e Gustav Marcus, alguns dos quais desempenharam papel fundamental na construção da fisiologia de Berlin, como Emil Du Bois-Reymond, por exemplo, que foi figura central no grupo de físicos orgânicos.
} 
orientadas para a pesquisa abstrata que se tornaram, mais tarde, base para a força industrial e militar da Alemanha ${ }^{7}$ ).

\section{Pesquisa rentável e o crescimento do conhecimento na Alemanha por volta de 1900}

Timothy Lenoir defende a tese de que o desenvolvimento de institutos de pesquisa com vistas ao lucro, na Alemanha na virada do século XX, ao contrário de ser ameaçador, foi fértil. Isto é, a curiosidade científica e o crescimento do conhecimento não foram inibidos em momentos em que a pesquisa científica foi conduzida num cenário de relacionamento complexo entre universidades, indústria e governo.

Por exemplo, o desenvolvimento em campos biomédicos da imunologia e do tratamento médico experimental - especialmente no Institut für Serum-Forschung und Experimentale Therapie de Paul Ehrlich - as principais ideias teóricas (a teoria da cadeia lateral para explicar a formação de anticorpos e o conceito correlacionado de quimiorreceptor) emergiram de problemas práticos associados ao desenvolvimento de soros terapêuticos e em quase todos os estágios o relacionamento com indústrias de corantes e medicamentos alemãs foi crucial. Isto levou Ehrlich a propor novos arranjos institucionais entre indústria e Estado com o fim de obter apoio à pesquisa, Isto evidencia, adverte Lenoir, que, "e fato, em certas situações críticas, o comprometimento da investigação científica com objetivos práticos tem sido essencial ao crescimento do conhecimento" (BEN-DAVID, 1971 apud LENOIR, 2004, p. 226).

Fora das universidades, por sua vez, um dos fatores que impulsionou a pesquisa na Alemanha foi a introdução de seguros de saúde e contra acidentes nos anos de 1880. "Essa política foi planejada por Bismarck como um meio para integrar a classe dos trabalhadores industriais na sociedade alemã” (ibid., p. 227) e teve como resultado o rápido crescimento de instalações hospitalares e cuidados médicos em todos os sentidos. Além disso, o crescimento da indústria e de cidades como Berlim criou uma grande demanda por saneamento público e higiene, que estimulou o Estado a participar ativamente na promoção da ciência médica e a apoiar a pesquisa voltada a problemas de saúde pública. Por outro lado, vários cientistas

\footnotetext{
${ }^{7}$ Um dos fatores que contribuíram à ascensão meteórica da Alemanha imperial foi, segundo Lenoir, o acolhimento dado à ciência; rendeu-lhe vantagens econômicas e ideológicas manter uma posição de liderança da produção do conhecimento científico. "Por volta de 1870, os alemães estavam rapidamente transformando sua cultura em uma cultura dominada por cientistas, ao passo que, ao longo da primeira parte do século, eles tinham definido seus heróis culturais como poetas e filósofos idealistas" (ibid., p. 169). Idealismo político significava um pensamento político orientado por ideais filosóficas e morais que representavam o interesse de grupos sociais particulares, ao passo que na metade desse século um grupo de pessoas e intelectuais politicamente ativos e marcados por ideias iluministas, racionalistas e de lei natural expandiu-se para incluir negociantes, industriais, jornalistas e até trabalhadores.
} 
eminentes $^{8}$ aproveitaram o momento para levar adiante pesquisas avançadas contra a difteria, tétano e tuberculose e obtiveram apoio à construção de institutos especializados. Alguns desses institutos puramente científicos foram criados fora das universidades e em cooperação com a indústria farmacêutica.

Ao mesmo tempo, a Alemanha esteve preocupada com o ambiente acadêmico, por exemplo, visando o crescimento da Física e da Matemática para atender às necessidades da indústria de mecânica de precisão. Mas em função das rígidas hierarquias das universidades alemãs, a solução, assevera Lenoir, foi uma política de colaboração entre a ciência acadêmica e a indústria, que reuniu tanto os interesses do estado quanto os da emergente indústria alemã. A indústria química Höchst foi um exemplo da colaboração estratégica entre indústria e universidade. A Höchst estava interessada no desenvolvimento lucrativo de preparos químicos e estabeleceu acordos com a Universidade de Geissen, que tinha o papel de procurar talentos promissores nos laboratórios da universidade e encorajá-los a trabalhar em tópicos de interesse da fábrica. Por outro lado, o pesquisador Paul Ehrlich foi beneficiado por essa política, pois desde o início de sua carreira foi abastecido com tinturas por químicos da Höchst e no processo de explorar o uso de corantes como agentes para o tingimento histológico ele se tornou um mestre na química de tinturas, explorando várias teorias a respeito de como as tinturas se fixam em fibras o que o levou a desenvolver uma teoria dinâmica da ação farmacológica (ibid., p. 233). De outro lado, a conexão com a Höchst foi importante para o trabalho de Ehrlich na teoria da imunidade e ele entrou em acordo com a fábrica, em 1892, para a produção em larga escala do soro de difteria e essa colaboração culminou com sua teoria da cadeia lateral como mecanismo para a reação de imunização (ou seja, a produção de vacinas).

Assim, defende Lenoir, antes de tratar universidades e indústrias como organizações fechadas, delimitadas, é preferível considerar a história de algumas empresas que souberam negociar fronteiras disciplinares e erigirem-se ao lado (não dentro) das paredes da universidade.

\section{Ciência, Indústria e Estado}

Nesse estágio, argumenta Lenoir, parecia possível transferir a bacteriologia e a química orgânica das instituições de pesquisa apoiadas pelo Estado para a produção. Mas, ao mesmo tempo, preponderavam as considerações com a saúde pública e havia uma preocupação com relação à potencial importância médico-militar da pesquisa sobre os soros.

\footnotetext{
${ }^{8}$ Lenoir cita o bacteriologista Robert Koch que foi diretor, ao mesmo tempo, do laboratório bacteriológico no Reichsgesundheitsamt e do Institut für Hygiene, na universidade de Berlim.
} 
Esses interesses fizeram o Estado pensar em reservar para si todos os direitos na produção dos soros terapêuticos. O Estado tinha responsabilidade de assegurar a qualidade e eficácia dos soros terapêuticos por empresas como a Höchst e, de modo similar, para promover a saúde pública (considerando a iniciativa do Estado quanto ao seguro de saúde para os trabalhadores) o governo tinha interesse em promover pesquisa e desenvolvimento de novas vacinas. $\mathrm{Ou}$ seja, precisava encorajar o desenvolvimento de soros terapêuticos e também estava interessado em pesquisa básica que possivelmente não encontrasse aplicações imediatas na indústria.

De outro lado, as indústrias Höchst tinham interesse em certas linhas de pesquisa, por exemplo, levar adiante o desenvolvimento e a produção de soros de difteria e tétano de Behring, que prometiam retorno substancial do investimento em pesquisa. Contudo, enquanto elas se beneficiavam da pesquisa básica, não era de seu interesse construir, elas mesmas, instalações elaboradas destinadas a pesquisas que não dessem retorno imediato. Em outras palavras, a política da Höchst de levar adiante a pesquisa com objetivos bem definidos era desejável, mas não estava interessada em expandir o conhecimento científico.

Assim, um primeiro resultado foi o estabelecimento do Institut für Serum-Prüfung und -Forschung, um instituto sem fins lucrativos, baseado na cooperação mútua entre Estado, indústria e academia. Tendo o pesquisador Paul Ehrlich como diretor, inicialmente esteve estabelecido em Berlim e foi transferido em 1899 para Frankfurt, unido ao laboratório Senkenbergische Akademie estava perto de seu maior consumidor, a Höchst. As instalações foram financiadas pelo Estado, pelo município de Frankfunt e por doações de empresas como a Höchst, Casella, Ferbwerke e patrocinadores individuais. Ainda que não fosse um instituição de ensino, o instituto dispunha de verbas para pagar estudantes que haviam completado seus estudos de medicina para trabalhar sob a orientação de Ehrlich e sua principal função era o teste de soros terapêuticos, a pesquisa bacteriológica e sanitária a hospitais e médicos locais e a pesquisa em imunologia (ibid., p. 243).

Em 1905 foi proposta uma instituição interdisciplinar, de quimioterapia experimental - o instituto Georg-Speyer-Haus - para definir problemas a serem enfrentados através da troca multilateral de ideias entre fisiologistas, bioquímicos, microbiologistas, bacteriologistas, farmacologistas e clínicos (p. 252). O instituto foi organizado como instituição autossustentável pela venda de sua pesquisa. A pesquisa, que combinava avanços da ciência básica com as necessidades da indústria, resultou na produção do Salvarsan, a primeira cura para a sífilis.

Para Lenoir, os desenvolvimentos que conduziram à instituição do Georg-SpeyerHaus e à disciplina do tratamento médico experimental ilustram uma nova fase nas relações 
entre ciência, indústria e Estado, que foi central para o desenvolvimento de sociedades industriais a partir do final do século XIX.

Argumenta ele que:

quando os cientistas acadêmicos e pesquisadores industriais em várias disciplinas começaram a formular os problemas críticos na organização do trabalho científico, que obstruíam o alcance de seus objetivos, eles inventaram uma forma institucional que lhes permitiu tanto remover impedimentos ao crescimento científico como fazer uma transição suave à aplicabilidade prática (ibid., p. 254).

Assim, propõe ele, em certas circunstâncias, a ligação da investigação científica com propósitos práticos pode ter consequências muito férteis para o desenvolvimento científico.

\begin{abstract}
Ao levar adiante esse tema, dediquei toda a minha atenção à visão da busca do conhecimento científico como profundamente engastada dentro da política e da economia da sociedade em que ocorre. Assim, tenho argumentado que, em vários de seus subsistemas, tanto interessados na produção do conhecimento científico como dela dependentes, a Alemanha imperial tinha encontrado obstáculos à conquista de seus objetivos econômicos e sociais mais amplos, bem como à realização de seus ideais. Para manter sua posição de liderança na ciência internacionalmente, o que era considerado uma questão importante no que se refere ao prestígio bem como ao valor econômico, tinha se tornado essencial romper com os modelos de organização disciplinar que haviam uma vez permitido que a ciência alemã ascendesse à primazia no mundo. (...). A flexibilidade e os recursos de figuras proeminentes da indústria química, por exemplo, permitiram experienciar novos padrões organizacionais para a condução da pesquisa científica, em particular com a formação de equipes interdisciplinares de especialistas trabalhando em problemas claramente definidos (ibid., p. 255).
\end{abstract}

Para Lenoir, esses institutos (seu sucesso) tiveram repercussões em todo o sistema, e novas formas de conhecimento (a imunologia, a quimioterapia experimental) foram criadas e tornaram-se base para reorganizar padrões disciplinares.

\title{
Stanford, universidade empreendedora, e o Vale do Silício
}

Em outro estudo de caso histórico Lenoir afirma que a Universidade de Stanford "é um exemplo paradigmático entre universidades geradoras de inovações que levam à criação de novas firmas de base tecnológica" (LENOIR, 2005, p. 239) e que a atividade empreendedora de Stanford é, em geral, considerada sinônimo do nascimento do Vale do Silício. Há estudos, defende ele, que mostram que ex-alunos e docentes de Stanford respondem por mais de 1.800 empresas de base tecnológica do Vale do Silício e são responsáveis por $37 \%$ de todos os empregos de alta tecnologia da região (e.g., a HewlettPackard).

Mas, defende ele, a interação de Stanford com a indústria não é um relacionamento de mão única. Ao contrário, embora essa universidade tenha desempenhado um papel importante na moldagem econômica da região, as empresas do Vale do Silício foram igualmente importantes na moldagem dos campos da pesquisa em Stanford. As grandes empresas de alta tecnologia, capitalistas de risco, instituições acadêmicas e governamentais de pesquisa 
formam um ecossistema de inovação e empreendedorismo marcado por fluxos dinâmicos entre o Vale e Stanford. A chave, argumenta Lenoir, para entender esses fluxos dinâmicos é o apoio financeiro dado pelo governo federal à pesquisa e ao desenvolvimento em universidades importantes, bem como o estímulo dado pela pesquisa à indústria em regiões de tecnologia. A Universidade de Stanford foi bem-sucedida na obtenção de recursos federais ${ }^{9}$ para a pesquisa científica, que fosse, ao mesmo tempo, industrialmente relevante. Embora a universidade conte com apoio industrial, este tem sido pouco significante, pois $90 \%$ de seu orçamento para pesquisa vem de fontes federais. Uma estratégia importante tem sido que os pesquisadores de Stanford nas áreas da biotecnologia, ciência de materiais, ciência da computação, engenharia elétrica e outros campos bastante compensadores em termos financeiros estão tornando-se, com encorajamento da direção da universidade, criados da indústria ao vender suas invenções a fim de financiar sua pesquisa e obter ganhos financeiros pessoais. O licenciamento das invenções (entre 1970 e 2003, obteve 5.324 divulgações de invenções e patenteou 1.371 invenções), no entanto, gera receitas relativamente pequenas em comparação com as necessidades de pesquisa da universidade.

Stanford desenvolveu uma estratégia eficiente para permanecer na pesquisa de ponta:

Por um lado, ela desenvolveu-se como uma instituição empreendedora, altamente flexível, que procura ativamente absorver novas áreas de avanço tecnológico e científico que surgem na indústria do Vale do Silício e em outros lugares e transformá-las em áreas de pesquisa científica merecedoras de apoio federal para a pesquisa. (...). Igualmente eficaz é a transferência de ideias, técnicas, pessoal e tecnologia de projetos de pesquisa com financiamento federal de Stanford para novas empresas na área do Vale do Silício, que, ocasionalmente, tornam-se pioneiras em novas áreas que transformam a paisagem da pesquisa (ibid., p. 241).

Para Lenoir, quando se examina a fundo as características de inovações geradas pela universidade o que faz a diferença é a existência de um ambiente que incentiva o trabalho colaborativo entre departamentos e faculdades (e. g., colaborações entre faculdades de engenharia e medicina, computação e biotecnologia, nanotecnologia e comunicação). Lenoir sustenta que o programa de licenciamento de tecnologia visando comercialização da pesquisa feita por Stanford não é só economicamente relevante, mas a interação com a indústria "produz ciência de ponta" e aumenta a vantagem competitiva dos pesquisadores da universidade na obtenção de financiamentos federais.

Além disso, estudos recentes mostram que a colaboração com a indústria tem tido efeitos positivos no sentido de aumentar a produtividade de cientistas de Stanford; o trabalho de "estrelas da ciência" desempenha um papel importante para determinar quais empresas que utilizam "descobertas" avançadas terão maior sucesso; além de esses cientistas publicarem,

\footnotetext{
${ }^{9}$ A fonte principal do orçamento de Stanford para a pesquisa é o governo federal através do Instituto Nacional da Saúde (NHI - National Institute of Health); a Fundação Nacional de Ciência (NSF - National Science Foundation), o Departamento de Defesa e outros órgãos governamentais (Lenoir, 2005, p. 241).
} 
muitas vezes, textos científicos em maior quantidade e de melhor qualidade durante o período em que estão envolvidos com a indústria, aparentemente devido aos maiores recursos resultantes de suas atividades comerciais.

Assim, defende Lenoir, o licenciamento e a transferência de tecnologia representam um intercâmbio de mão dupla, no qual ocorrem trocas de conhecimento, ideias e práticas (ibid., p. 300).

\section{Considerações finais}

Estamos convencidos de que é importante aceitar a validade de estudos históricos, como nos mostra com enorme habilidade e coerência argumentativa Timothy Lenoir, mas também aceitamos que é preciso ter cuidado para não estender demais teses sobre a ciência com base em certos episódios locais para não passar a ideia de que o conhecimento científico é subjetivo ou pouco confiável. De qualquer modo, é inegável que as disciplinas científicas, na maioria das vezes, são instituídas em contextos "externos" à própria ciência. Resultam da combinação de condições políticas, econômicas e sociais. Como defende Lenoir, $o$ "conhecimento científico é socialmente construído, mas isto não quer dizer que seja fictício, subjetivo, arbitrário ou irracional" (ibid., p. 256), ao contrário, ele fornece explicações confiáveis incorporando os aspectos sociais.

Defendemos que refletir a forma como os avanços científicos são alcançados é de importância indiscutível para problematizar a educação científica. Também é inevitável considerar que a ciência moderna é cada vez mais mediada pela técnica e pela moderna instrumentação e neste ponto ela depende da indústria, que, por sua vez, é alavancada pelo avanço do conhecimento científico. Nesse sentido é que Lenoir nos fala que ciência e indústria estão "muro a muro" contribuindo mutuamente e gerando desenvolvimento. Assim, a visão de ciência de Timothy Lenoir auxilia-nos a perceber a existência de conexões frutíferas entre indústria, universidade, Estado e a compreender melhor o contexto de produção do conhecimento científico.

Poderíamos refletir sobre se essa conexão frutífera entre universidade e indústria, ou melhor, entre pesquisa científica (usualmente feita na universidade) e indústria existe em todos os países? Lenoir toma como exemplos, em seus estudos de caso, a Alemanha e os Estados Unidos. Mas como seria essa conexão em países onde a "indústria" é apenas montadora ou em países onde há pesquisa científica, mas dela resultam apenas "papers" e quase nenhuma patente de natureza tecnológica? Isso ocorre não apenas em países subdesenvolvidos ou ainda em desenvolvimento, mas também, provavelmente, naqueles dos "BRICS". Mas isto não deixa de ser um ponto de reflexão: se levássemos em conta tais conexões em países subdesenvolvidos, possivelmente teríamos que ou admitir que não fazem 
ciência ou teríamos que modificar muito nossa noção de ciência. Como dito, isto tudo também incita à reflexão.

Por outro lado, os vínculos destacados por Timothy Lenoir em seus detalhados e consistentes estudos de caso mostram as condições "concretas" e situadas em que se dá a ciência enquanto conhecimento que se faz sempre "localizado"; aclaram as interfaces entre ciência e indústria, a economia, a sociedade, os grupos profissionais, em momentos de grandes desenvolvimentos. Isto pode ajudar professores a estudantes a perceberem que compreender o surgimento de uma nova disciplina, de um novo conceito, ou uma "descoberta" científica, por exemplo, vai além de fazer uma reconstrução lógica da investigação científica. Requer uma abordagem complexa, pressupõe reconhecer que a ciência não é desinteressada, não é uma atividade baseada no "conhecimento pelo conhecimento" nem é autônoma. Na maioria das vezes a as disciplinas científicas surgem da combinação de fatores "externos" à própria ciência, de maneira que a análise desses contextos torna-se fundamental para a compreensão das circunstâncias, dos pressupostos teóricos e dos conceitos científicos em si.

Ignorar novas visões de ciência, como a que aqui foi interpretada e discutida, seria negar à educação científica um conjunto de elementos férteis à reflexão. Uma reflexão que, possivelmente, tornaria as aulas mais críticas e atrativas. Ensinar e aprender ciência é muito mais do que lidar com definições, fórmulas, equações, reações químicas, taxonomias.

\section{Referências}

BARDIN, L. Análise de Conteúdo. Lisboa: Edições 70, $3^{\text {a }}$ ed., 2004.

BATISTA, G. L. F.; DRUMMOND, J. M. H. F.; FREITAS, D. B. Fontes primárias no ensino de física: considerações e exemplos de propostas. Caderno Brasileiro de Ensino de Física, v. 32, n. 3, p. 663-702, 2015.

BEN-DAVID, J. The Scientist's Role in Society: a comparative study. Englewood Cliffs, N.J.: Prentice-Hall, 1971.

BOURDIEU, P. Outline of a Theory of Pratice. Cambridge: Cambridge University Press, 1977.

CARTWRIHT, N. How the Laws of Physics Lie. New York: Oxford University Press, 1983.

ECO. U. Come si fa una tesi di laurea: le materie umanistiche. Trebaseleghe/Pádua: Bompiani/RCS Libri, 2016.

HACKING, I. Representing and intervening: introdutory topics in the Philosophy of Natural Science. Cambridge: Cambridge University Press, 1983.

HOLMES, F. L. Lavoisier and the Chemistry of life: an exploration of scientific creativity. Madison: University of Wisconsin Press, 1985. 
LATOUR, B.; WOOLGAR, S. A Vida de Laboratório: a produção dos fatos científicos. Rio de Janeiro: Relume Dumara, 1997.

LEDERMAN, N. G. Nature of science: past, present and future. In: ABELL, S. K.; LEDERMAN, N. G. (Eds.). Handbook of Research on Science Education. Mahwah, New Jersey: Lawrence Erlbaum Publishers, 2007. p. 831-880.

LENOIR, T. Instituindo a Ciência: a produção cultural das disciplinas científicas. São Leopoldo: Editora da UNISINOS, 2004.

LENOIR, T. Inventando a universidade empreendedora: Stanford e a co-evolução do Vale do Silício. In: REGNER, A. C.; ROHDEN, L (Org.) A Filosofia e a Ciência redesenham horizontes. Orgs.. São Leopoldo: Editora da UNISINOS, 2005.

MARTINS, R. A. Introdução. A história das ciências e seus usos na educação. In: SILVA, C. C. (Org.). Estudos de história e filosofia das ciências: subsídios para aplicação no ensino. São Paulo: Livraria da Física, 2006, p. xxi-xxxiv.

MERTON, R. Sociology of Science: theoretical and empirical investigations. Chicago: University of Chicago Press, 1973.

PEDUZZI, L. O. Q. Sobre a utilização didática da História da Ciência. In: PIETROCOLA, M. (Org.). Ensino de Física: conteúdo, metodologia e epistemologia numa concepção integradora. Florianópolis: Ed. da UFSC, 2001. p. 151-170.

PICKERING, A. Forms of life: science, contingency and Harry Collins. British Journal for the History of science, vol. 20, p. 213-221, 1987.

RAICIK, A. C.; PEDUZZI, L. O. Q. A estrutura conceitual e epistemológica de uma descoberta científica: reflexões para o Ensino de Ciências. Alexandria: Revista de Educação em Ciência e Tecnologia, v.9, n.2, p.149-176, 2016.

REGNER, A. C. K. P.; LEAL, H. M. Racionalidade: uma discussão lateral com Timothy Lenoir. Episteme, v. 2, n. 4, p. 127-134, 1997.

\section{SOBRE OS AUTORES}

NEUSA TERESINHA MASSONI. Licenciada (2000), Mestre em Física (2005) e Doutora em Ciências (2010) pela Universidade Federal do Rio Grande do Sul - UFRGS, com ênfase na área de Ensino de Física; atualmente é Professora Adjunta da Universidade Federal do Rio Grande do Sul e docente permanente do Programa de Pós-Graduação em Ensino de Física do Instituto de Física da UFRGS.

MARCO ANTONIO MOREIRA. Licenciado (1965) e Mestre em Física pela Universidade Federal do Rio Grande do Sul - UFRGS, Doutor em Ensino de Ciências (1977) pela Cornell University/USA, atualmente é Professor Emérito da UFRGS e docente permanente do Programa de Pós-Graduação em Ensino de Física do Instituto de Física da UFRGS; é professor colaborador da Universidade de Burgos/Espanha; integrou o Comitê de Educação do CNPq de 19931995 e de 1999 a 2001; é pesquisador 1a do CNPq, na área de Educação, desde 1989, tendo orientado dezenas de mestrados e doutorados. 
Recebido: 24 de junho de 2016 .

Revisado: 09 de março de 2017.

Aceito: 17 de abril de 2017. 